Article

\title{
Does Student Proactivity Guarantee Positive Academic Results?
}

\author{
J. M. Cansino 1,2,*iD, Rocío Román ${ }^{1,2}$ and Alfonso Expósito ${ }^{1}$ (i) \\ 1 Departamento de Análisis Económico y Economía Política, Universidad de Sevilla, 41.018 Seville, Spain; \\ rroman@us.es (R.R.); aexposito@us.es (A.E.) \\ 2 Universidad Autónoma de Chile, Santiago 7500912, Chile \\ * Correspondence: jmcansino@us.es; Tel.: +34-954-557528
}

Received: 14 February 2018; Accepted: 19 April 2018; Published: 26 April 2018

\begin{abstract}
This paper analyzes the impact of students' proactivity on academic performance based on a sample from students enrolled in an introductory course of Political Economy at the University of Seville (Spain) in three consecutive courses (2014-2015, 2015-2016 and 2016-2017). Proactivity is measured by several indicators, such as class attendance, case-study oral presentation and its delivery in a foreign language, all of them being non-mandatory activities for students who have participated in the experiment. Specifically, this study aims to assess the impact of a student's proactivity on two academic outcomes: (i) to pass or fail the exam; and (ii) the score obtained. Impact assessment has been performed using a probit and ordered multinomial logit models. The results show that a student's proactivity measured by class attendance and case-study presentation significantly increases the probability of passing the exam, while the impact of using a foreign language seems to be non-significant. In relation to the score obtained, the proactivity measured through the case presentation raises the probability of obtaining a higher mark more than regular class attendance.
\end{abstract}

Keywords: student proactivity; class attendance; academic performance

\section{Introduction}

The existing literature highlights student profile [1], educational infrastructure [2], quality of education [3], education policies [4-6], professional teacher training [7], teacher perception [8], family and community relationship with the educational institutions [9] and the type of institutional educational establishment [10-12] as the most relevant factors to explain students' academic performance. However, most of these studies focus on pre-university education.

At university level, and since the seminal paper by Romer [13], international literature has focused on the role of student proactivity in their academic performance, with proactivity being considered, in general, as lecture attendance. When teaching is based on recommended bibliography and educational resources prepared by the lecturer, the question arises: to what extent is classroom teaching really necessary? This is especially true when the evaluation system does not require class attendance. Furthermore, it is generally perceived that students attend class more often when the quality of instruction is higher [13].

If class attendance fails to significantly impact on the probability of passing an exam or on the mark obtained, then relevant questions appear for the university system. Student location decisions are affected when class attendance is not mandatory or is irrelevant for academic success. In such cases, students may maintain their usual residences, or travel occasionally to take their exams, with which training costs are reduced. On the other hand, when class attendance does not affect academic success, other issues arise of a more budgetary nature and matter to the university. For example, there is an increase in the possibilities of e-learning systems, ICT (Information and Communication Technologies) 
needs rise, but personnel and infrastructure costs could be reduced significantly. Universities could more efficiently allocate resources among the various teaching modes requiring different amounts of instructional time. Students could use class attendance information to influence academic performance; at the same time, they could improve time-allocation efficiency [14].

In line with Romer [13], literature shows that class attendance has a positive and significant impact on academic performance [15-32]. However, some studies also offer evidence that class attendance is not a predictor of academic outcome [14,33-36].

Upon reviewing the literature, evidence identifying causality in the attendance-performance relationship still offers inconclusive results; therefore, further research is required. This study aims to contribute to the existing literature by analyzing the relationship between lecture attendance and academic performance, as well as by incorporating a broader perspective when measuring student proactivity. Our study strives to capture student proactivity in a more extensive manner by including variables such as oral case-study presentations in a second language (usually in English, but with some students using French or Italian for their oral presentations), all of which goes well beyond mere class attendance. Furthermore, these student proactivity measurements reflect other students' endogenous capacities that may affect their academic performance $[37,38]$. Consequently, to extend the scope of previous studies, this research field attempts to answer the following questions: Does class attendance positively affect the probability of passing the exam and obtaining higher scores? Is inducing student proactivity through oral case-study presentations improve academic outcomes (i.e., to pass the exam and to achieve higher scores) effective?

This study has been carried out at the University of Seville Faculty of Law with students from three consecutive courses taking the subject Political Economy (2014-2017), with a total of 518 observations. Case study and method are described in detail in subsequent sections. The methodology used to answer our research questions is based on the use of probit and ordered multinomial logit models. This approach is unusual in the literature when dealing with the topic addressed by this paper, which is mainly based on ordinary least square (OLS) regressions. Two exceptions using probit models are $[39,40]$. The method proposed in this study seeks to contribute to the use of alternative econometric models. The structure of probit and logit models is designed for binary outcomes (or categorical outcomes in the case of multinomial regressions), whereas OLS is not. Furthermore, probit and logit regression results could be comparable to those of OLS in many respects as they provide more accurate predictions for the probabilities of the dependent outcome [41].

Thus, the main contributions of this paper to the literature derive from the broader definition of proactivity, the large size of the sample supporting it and the use of a methodological approach other than OLS. The main results of the evaluation reveal that student proactivity significantly increases the probability of passing the test. With regards to the mark obtained, proactivity measured through case presentation elevates the probability of obtaining a higher mark more than regular class attendance.

\section{Case Study}

At the university level, the relationship between students' class attendance and their academic performance has attracted special attention. There are examples of class attendance studies and academic performance: Macroeconomics [13,14,42,43]; Econometrics [44]; Principle of Economics [45]; and Agricultural Economics [46], among others. To the best of our knowledge, the available literature does not offer any examples focused on Law faculties.

In our specific case, the subject of Political Economy is part of the Degree in Law at the University of Seville (Spain) and consists of an introduction to the theory of political economy. At the University of Seville, an e-learning system has not yet been implemented and although class attendance is not mandatory, the system basically consists of "face-to-face" lectures. Political Economy is a 6-credit subject in the European Credit Transfer System (ECTS), similar to that studied by [31]. The ECTS is defined as a standard for comparing study attainment and the performance of higher education students throughout the European Union and other collaborating European countries. At Spanish 
universities, to pass a given course, enrolment in a specific course provides students with two opportunities to take exams (first call and second call). The relationship between proactivity and academic performance was established only with those students who participated in first call exams in February. The exam to be passed is defined as a multiple-choice test.

In our study, proactivity was not only being measured by class attendance, but also by an oral case-study presentation in a second language. Presenting the case study or attending class are non-mandatory activities for the participating students. The case-study presentation is based on a firm that is sufficiently representative of Spanish or international economy and whose activity highlights the aspects most directly related to the academic content of that subject. Examples are business tax obligations, their relationship with Public Administrations and/or their stakeholders. The main information supporting the case study must be freely accessible on-line for verification. The use of ICTs for case-study presentation is mandatory.

The presentation and assessment of case studies was as follows: students submit a draft version of their presentations to the professor using the virtual platform. Under the supervision of the professor, the case study is supervised to decide the adequacy of the topic. For deadlines, a calendar to submit case-study presentations is published and used automatically as a calendar tool. Once the professor approves the final version, it is made available to the students in each group. There is a specific folder on the virtual platform to file case-study presentations. The presentation file (usually Power Point or Prezi slides) is made available, in advance, to the audience on a virtual teaching platform. Students, and the teacher, may send their questions to the platform and access the folder using mass electronic devices such as laptops, tablets, or smart phones. Thanks to this tool, the number of downloads for each presentation is known. It is noteworthy that the University of Seville provides students and professors with internet access thanks to the roaming access service eduroam-education roaming, www.eduroam.org/ [47-49].

Once authorized and using ICTs, students present their case studies in class without exceeding a 10-min time limit. All presentations are subject to questions and comments from their peers during the face-to-face session. Presenting the case study in another language was optional for all students. Students consider it as an extra challenge to develop or improve their communication skills in a second language.

\section{Method}

\subsection{Participants}

On average, some 500 students enroll annually in Political Economy at the University of Seville, Faculty of Law during the first semester of their first academic year. The number of students participating in this study is approximately 30 percent of the total; they correspond to three groups attending morning lecture sessions. During the three courses in which the study was carried out, there have been no changes in the schedule of the groups selected, with all being morning groups leaded by the same lecturers. The experiment population was not previously informed about the project to avoid Hawthorne type effects [50]. There were no changes in the standard required to access the University, in the academic content of the subject, in the didactic resources used or in the type of the exam, or in the standard to pass the exam.

\subsection{Procedure}

Data were collected manually for those variables that capture student proactivity, while the gender variable was derived directly from the student census. Most case presentation data were taken from the virtual teaching platform. A case-study presentation register was obtained when students sent the digital file to their professor (via email or using the virtual teaching platform). The file-once supervised by the professor-was hosted on the virtual teaching platform and remained available for the audience prior to presentation. 
The University of Seville virtual teaching platform offers both students and professors a variety of tools, such as space for virtual discussion and collaborative endeavors, team work, didactic electronic resources, the possibility of sending e-mails to selected groups and an evaluation system, among other aspects. This platform also provides discussions about making public presentations by [51-55].

All class attendance information was also collected manually and processed in an Excel file. For this specific type of research, careful attendance monitoring is a crucial component. A sign-in sheet was passed around in class and signed by all students in attendance. Teaching events were chosen randomly. The verification attendance sheet included both the date and group, and students recorded their names and ID or passport numbers. Before the class session concluded, each professor verified all information to avoid any possible limitation found in studies based on students' memory [29].

Exam score data was from the first annual exam (first call) held at the beginning of February. At this first call, there is massive attendance, therefore it is taken as a reference for this experiment. This multiple-choice exam ( 25 questions with three options, only one is right) is designed to penalize wrong answers but does not reward omissions.

\subsection{Data Analysis}

Table 1 provides a description of the variables used in our analysis. The descriptive statistics of Table 2 show that only fifty-three percent (53\%) of the students passed the exam. The average mark achieved in the sample is 1.71 (scale 1 to 4 , where 2 is a pass); thus, on average, the marks attained by the students are low (specifically, below 5 in a scale from 0 to 10). Moreover, class attendance is also low, as shown by the average value of the variable "attend", and only twenty percent $(20 \%)$ of the students opted for voluntary class presentations to reinforce their learning process. Female students represent $56 \%$ of our sample. These preliminary descriptive analyses shed additional light on our hypothesis: class attendance and case-study presentations do not seem to be generally adopted by the student community as determinant factors for academic success. Case-study presentation in a second language was chosen by ( $8 \%$ ) of our student sample. Finally, gender was also taken into consideration as a potential moderating variable $[56,57]$.

Table 1. Description of Variables.

\begin{tabular}{lll}
\hline Name & Type & Definition \\
\hline $\begin{array}{l}\text { Dependent variables } \\
\text { Pass }\end{array}$ & Binary & Whether the student has passed the exam $(=1)$ or not. \\
Mark & Multinomial & 4 (marks between 8.5 and 10$) ; 3$ (between 7 and 8.49$) ; 2(5$ and 6.99$) ; 1$ (below 5). \\
\hline $\begin{array}{l}\text { Explanatory variables } \\
\text { Attendance }\end{array}$ & Categorical & Values within the range (0-8), as given by eight attending tests. \\
Presentation & Binary & Whether the student has voluntarily presented a case study in class (=1) or not. \\
Language & Binary & Whether the student has made the presentation in a foreign language $(=1)$ or not. \\
Gender & Binary & Whether the student is female $(=1)$ or not. \\
\hline
\end{tabular}

Table 2. Descriptive statistics.

\begin{tabular}{ccccccc}
\hline & Pass & Mark & Attendance & Presentation & Language & Gender \\
\hline Mean & 0.539 & 1.717 & 1.676 & 0.203 & 0.167 & 0.564 \\
Standard Deviation & 0.498 & 0.796 & 1.523 & 0.402 & 0.374 & 0.496 \\
\hline
\end{tabular}

\subsection{Analytical Instruments}

To study the impact of student attendance (as a student's proactivity measure) together with other proactivity variables such as the case-study presentation and the case being presented in another language, a two-step analysis was conducted. Firstly, to study whether these variables have a direct impact on passing the exam, a binary outcome model has been used. A common example of this 
binary model is probit regressions. In a second step, an ordered multinomial logit model was applied to research the relationship between our explanatory variables and the exam scores obtained by the students. The proposed methods facilitate the analysis of the significance of the class attendance impact on the probability of passing exams (binary probit model) and obtaining higher exam scores (multinomial logit model), together with other relevant measures of student proactivity, such as the voluntary, oral case-study presentations by students in a second language.

The first step is based on the use of a probit model. As previously mentioned, these models enable us to analyze whether student proactivity results offer a higher predicted probability of passing the exam, under a ceteris paribus assumption. Consequently, the specification of our model to be tested can be expressed by Equation (1):

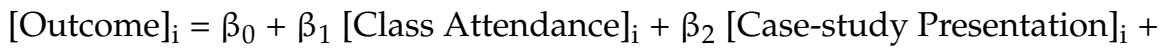

$$
\begin{aligned}
& \beta_{3}[\text { Second language }]_{i}+\beta_{4}[\text { [Gender }]_{i}+\varepsilon_{i}
\end{aligned}
$$

where the variable "Outcome" represents the binary outcome (passing the exam), taking a value equal to 0 if the student failed the exam or a value equal to 1 if the student passed it, as a function of the explanatory variables considered. The term error is understood to be iid $\sim\left(0 ; \sigma_{\varepsilon}\right)$.

Generally, binary outcome models, as is the case of probit models, are constructed upon a dependent variable, $\mathrm{y}_{\mathrm{i}}$, that admits only two possible values ( 1 or 0$)$ and each value has an associated probability ( $p$ if $y_{i}=1$ and $1-p$ if $y_{i}=0$ ). In this case, variable $y_{i}$ takes the value 1 if the probability of that alternative exceeds the probability associated with option 0 , and vice versa. See [41] for a further explanation of the econometric specification of these models.

As the estimated $\beta$ parameters are not directly interpretable (apart from the sign), marginal effects of the regressors at the mean are estimated. As these alternative parameters are fully interpretable in sign and value, they show how much the (conditional) probability of the outcome variable changes when one changes the value of a specific regressor under a ceteris paribus assumption (holding all other regressors constant at some values). In our specific case, two alternative simple probit regressions (whether the student takes the exam or not, and whether the student passes or not) have been run separately. Both estimated $\beta$ parameters and marginal effects are shown and discussed in Section 4.

Finally, a second step analysis is carried out upon an ordered multinomial logit regression. In our case, the ordered outcomes (i.e., exam scores) are modelled to arise sequentially as a latent variable $\left(\mathrm{y}_{\mathrm{i}}^{*}\right)$, progressively crossing higher thresholds (a jump from an inferior to a superior category). Thus, for individual $i$, the regression is specified as:

$$
y_{i}^{*}=x_{i}^{\prime} \beta+u_{i}
$$

In the case of an m-alternative ordered model, we define

$$
y_{i}=j \quad \text { if } \alpha_{j-1}<y_{i}^{*} \leq \alpha_{j}, \quad j=1, \ldots, m
$$

where $\alpha_{0} \rightarrow-\infty$ and $\alpha_{\mathrm{jm}} \rightarrow \infty$. Then

$$
\begin{aligned}
\operatorname{Pr}\left(y_{\mathrm{i}}=\mathrm{j}\right) & =\operatorname{Pr}\left(\alpha_{\mathrm{j}-1}<\mathrm{y}_{\mathrm{i}}^{*} \leq \alpha_{\mathrm{j}}\right) \\
& =\operatorname{Pr}\left(\alpha_{\mathrm{j}-1}<\mathrm{x}_{\mathrm{i}}^{\prime} \beta+\mathrm{u}_{\mathrm{i}} \leq \alpha_{\mathrm{j}}\right) \\
& =\operatorname{Pr}\left(\alpha_{\mathrm{j}-1}-\mathrm{x}_{\mathrm{i}}^{\prime} \beta<\mathrm{u}_{\mathrm{i}} \leq \alpha_{\mathrm{j}}-\mathrm{x}_{\mathrm{i}}^{\prime} \beta\right) \\
& =\mathrm{F}\left(\alpha_{\mathrm{j}}-\mathrm{x}_{\mathrm{i}}^{\prime} \beta\right)-\mathrm{F}\left(\alpha_{\mathrm{j}-1}-\mathrm{x}_{\mathrm{i}}^{\prime} \beta\right)
\end{aligned}
$$

where $F$ is the cumulative distribution function (c.d.f.) of ui. The regression parameter $\beta$, and the $m-1$ threshold parameters $\left(\alpha_{1} \ldots \alpha_{m-1}\right)$ are obtained by maximizing the log likelihood with $p_{i j}=\operatorname{Pr}\left(y_{i}=j\right)$ as defined above. In our ordered model, u corresponds to the c.d.f. of the logistic distribution. 
Contrary to the case of simple probit regressions, estimated marginal effects in multinomial logit regressions measure the impact on the probability of observing each of several outcomes (in this case, the different marks achieved by the students), rather than the impact on a single conditional mean [41]. This fact makes multinomial outcome mo6dels superior to simple binary models as they provide a wider range of conclusions drawn from alternative outcomes. Furthermore, the sign of the regression parameters may be directly interpreted as determining whether the latent variable increases with the regressor. Nevertheless, estimated marginal effects offer information about the impact of each regressor in terms of the probability of this outcome occurring.

In our specific case, the multinomial variable "mark" takes value 1 if the student achieves an exam mark below 5 (i.e., fails), value 2 if the mark obtained by the student is between 5 and 7 , value 3 if the student achieves a mark between 7 and 8.5, and finally value 4 if a mark is over 8.5 (up to 10) is obtained. Thus, our model presents three threshold parameters. The estimated marginal effects, shown in Section 4, help us identify how our proactivity measures (class attendance and case presentation) may impact on the marks obtained by the students in probability terms and under a ceteris paribus assumption.

This study seeks to assess the impact of class attendance, together with other alternative student proactivity measures on academic performance, rather than analyze personal abilities that may help achieve better performance outcomes (i.e., exam scores). The authors are aware of a potential endogeneity bias. Proactivity is potentially endogenous given that student performance could be positively affected by unobservable student characteristics, such as ability, effort, and intrinsic motivation [14]. The existing literature has tried to minimize endogeneity bias mainly through the inclusion of variables such as average pre-university score, cumulative grade point average and SAT scores, among others [58]. Nonetheless, the results are usually non-conclusive. This study aims to minimize endogeneity bias by including a voluntary, case-study presentation delivered orally in a second language as measures of the intrinsic student motivation, thus considering these variables as alternative proactivity measures to that of class attendance.

\section{Results and Discussion}

Models that include several variables reflecting the alternative dimensions of a subject, such as class attendance and a case presentation of student proactivity might be subject to multicollinearity problems. The variance inflation factors range from 1 to 4.8 for the explanatory variables in our models tested. Since all scores are far below critical cut-off points, multicollinearity is ruled out [59].

Table 3 displays the estimated correlation matrix. All correlations are statistically significant (at a $5 \%$ significance level), which is coherent with our research hypotheses.

Table 3. Correlation matrix.

\begin{tabular}{ccc}
\hline & Pass & Mark \\
\hline Attendance & 0.236 & 0.246 \\
Presentation & 0.239 & 0.248 \\
Language & 0.215 & 0.224 \\
\hline
\end{tabular}

Following the proposed two-step analysis, Table 4 reports the estimated marginal effects; these are calculated from the means of the individual marginal effects, for our two probit models. The variable "pass" was used to analyze whether student proactivity significantly affected the probability of passing the exam. For this, the estimated marginal effects from the estimated probit regression using robust variance estimators are sown in Table 4 . These results are shown in Table 4. The estimated p-values are given between brackets. 
Table 4. Estimated marginal effects from probit model.

\begin{tabular}{cc}
\hline & Pass \\
\hline Attendance & $0.064^{* * *}(0.000)$ \\
Presentation & $0.287^{* *}(0.014)$ \\
Language & $-0.091(0.785)$ \\
Gender & $-0.091^{* *}(0.019)$ \\
Wald Chi2 & 53.23 \\
Pseudo R2 & 0.079 \\
Correct. Classified & 64.58 \\
\hline Cote: & $* * * *$ Statistical significance at $1 \%$ and $5 \%$ levels, respectively.
\end{tabular}

The results support our hypothesis that student proactivity increases the probability of improved academic performance (measured by their ability to pass the exam). Specifically, both class attendance and case-study presentation increase the likelihood of passing the exam (under a ceteris paribus assumption). In fact, the impact is much higher ( $29 \%$ increase on the probability of passing the exam) if the student decides to actively participate in the class presenting a case study orally than when the student simply attends classes (6.4\%). With regards to presenting the case study in a second language, the estimated marginal effect is not statistically significant. In the case of gender as a moderating factor, interestingly it impacts negatively on passing the exam. Specifically, in gender terms, females reduce the probability of passing the exam by nine percent $(9 \%)$. These results are in line with the existing literature [56,57,60-62]. Only [33] found that the influence of regular attendance on exam performance was more important for female students than for males.

To analyze the impacts of our students' proactivity measures on their academic marks, our research has considered taking a second step. To do so, an ordered multinomial logit regression has been used. Table 5 presents the estimated marginal effects for the four values of our defined "mark" variable (as presented in Section 2 and described in Table 1). Estimates of cut-off thresholds do not present significant problems (at a 5\% significance level) and again robust variance estimates have been used to obtain heteroskedasticity-consistent standard errors.

Table 5. Estimated Marginal Effects from a Multinomial Logit.

\begin{tabular}{ccccc}
\hline & $\mathbf{( 1 )}$ & $\mathbf{( 2 )}$ & $\mathbf{( 3 )}$ & $\mathbf{( 4 )}$ \\
\hline Attendance & $-0.033^{* *}(0.011)$ & $0.013^{* *}(0.013)$ & $0.012^{* *}(0.013)$ & $0.005^{* *}(0.030)$ \\
Presentation & $-0.230^{* *}(0.015)$ & $0.097^{* *}(0.020)$ & $0.091^{* *}(0.019)$ & $0.041^{* *}(0.027)$ \\
Language & $0.023(0.824)$ & $-0.009(0.824)$ & $-0.009(0.824)$ & $-0.004(0.824)$ \\
Gender & $0.132^{* * *}(0.000)$ & $-0.056^{* * *}(0.001)$ & $-0.052^{* * *}(0.001)$ & $-0.023^{* * *}(0.005)$ \\
Observations & \multicolumn{2}{c}{$518^{2}$} \\
Wald Chi2 & \multicolumn{2}{c}{39.21} \\
Pseudo R2 & \multicolumn{2}{c}{0.038} \\
\hline
\end{tabular}

Note: ${ }^{* * *},{ }^{* *}$ Statistical significance at $1 \%$ and $5 \%$ levels, respectively. Model adjusted correctly.

Based on the estimated marginal effects when our ordered multinomial variable takes value 1 , the following conclusions may be extracted. Specifically, class attendance significantly reduces the probability of getting an exam score below 5 (in a scale ranging from 0 to 10) or, in other words, of failing the exam, by 3.3 percent. Similarly, a case study presentation reduces this probability by 23 percent. Thus, this type of proactivity seems to play a more significant role in explaining students' academic results, as will be confirmed from the estimated marginal effects when our multinomial variable takes higher values. In this regard, the probability of obtaining a value of 2 (a score between 5 and 7) significantly increases with class attendance and with class presentation 1.3 and 9.7\%, respectively, hence confirming the superior capacity of case-study presentation (as a proactivity measure) to pass the exam (in line with the results of the probit regression). Similar findings are obtained for the cases of values 3 and 4 . For instance, the probability of our dependent variable taking value 4 increases $4.1 \%$ 
when students opt for a case-study presentation, but only 0.5 percent with simple class attendance. Once again, oral presentations in a second language fail to impact on the probability of obtaining higher scores, as shown by the non-statistically significant marginal effects. Regarding the gender variable, the results confirm previous findings observed in the probit regression used to test the probability of passing the exam. Being female seems to negatively impact on the probability of getting higher marks, as shown by the estimated marginal effects in Table 5 .

Based on the above findings, the following may be stated. First, the empirical results obtained from our sample of students have shown that student proactivity plays a significant role in explaining academic outcomes, measured by their capacity to pass the exam and obtain higher scores. Although these findings are in line with the literature reviewed [14,29-32], no previous research incorporated alternative proactivity measures (such as case-studies presented orally in a second language) together with class attendance, nor has it tested the effect of proactivity measures on performance using both binary and multinomial probabilistic models.

\section{Conclusions and Recommendations}

This study assesses the impact of student proactivity on academic performance by means of a wide sample of students enrolled in an introductory course on Political Economy at the University of Seville Faculty of Law over three academic years. This paper contributes to the debate concerning the usefulness of face-to-face university lectures with a remarkable use of ICTs. The main novelty of our study, compared with previous literature on this subject, is not only to test the influence of class attendance on students' academic performance but also other measures of student proactivity, such as making a case-study presentation with intense use of ICTs and its delivery in a second language. To the best of our knowledge, this is the main contribution of our study to the existing literature, as well as the alternative analytical methods used.

The experiment carried out is easily replicable in other contexts. It also allows quality data to be obtained with hardly any budgetary resources. The methodology used (probit and ordered multinomial logit models) is sufficiently tested in the scientific literature but unusual in previous studies focusing on testing the impact of class attendance on academic performance.

In the light of the results obtained, it may be concluded that classroom teaching offers the possibility for students to develop a proactive attitude that has a positive impact on their probability of passing the final exam and obtaining a higher mark. Also, the results for the relationship between class attendance and academic performance contribute to the literature in line with the seminal paper of [13]. Despite this, we agree with the authors who do not recommend establishing mandatory attendance policies. Analyzed separately, the most demanding proactive behavior, a case-study presentation, contributes most importantly to academic performance. Additionally, it should be borne in mind that the presentation of a case study by the students usually enables them to connect academic content with their future professional development more accurately. It also provides them with a better knowledge of the business world that will be their main area of professional interest in the future in the case of developing their training in the business field.

These results may be used at the start of a new course to motivate students to take on the proactivity actions analyzed (class attendance and case-study presentation) because they are demonstrably related with academic performance. Students could use this information to improve the efficiency of their efforts. These results may have a motivation effect on lecturers as their teaching matters for student performance. We believe that it is very important to clearly inform students about the benefits of these proactivity actions for academic performance.

Finally, we believe that these findings have an important implication for the equity issue in education. Case presentations do not usually require the spending of money, but they do increase fairness by reducing the gap between students from high-income and low-income families. 
Author Contributions: José M. Cansino and Rocio Román conceived and designed the experiment. They also collected data. Alfonso Expósito analyzed the numerical data and carried out the econometric analysis. All authors contributed to the final manuscript.

Acknowledgments: The authors acknowledge the funding received from the SEJ 132 project of the Andalusian Regional Government of Andalusia (Spain) and the Department of Economic Analysis and Economic Policy at the University of Seville. J. M. Cansino and R. Román also acknowledge support from Universidad Autónoma de Chile (Chile).

Conflicts of Interest: The authors declare no conflict of interest.

\section{References}

1. Sanzana, M.B.; Garrido, S.S.; Poblete, C.M. Profiles of Chilean students according to academic performance in mathematics: An exploratory study using classification trees and random forests. Stud. Educ. Eval. 2015, 44, 50-59. [CrossRef]

2. Murillo, F.J.; Roman, M. School infrastructure and resources do matter: Analysis of the incidence of school resources on the performance of Latin American students. Sch. Eff. Sch. Improv. Int. J. Res. Policy Pract. 2011, 22, 29-50. [CrossRef]

3. Hanushek, E.; Woessmann, L. Education and economic growth. In International Encyclopedia of Education, 3rd ed.; Elsevier: Oxford, UK, 2010; Volume 2, pp. 245-252.

4. Gershberg, A.; Meade, B.; Andersson, S. Providing better education services to the poor: Accountability and context in the cast of Guatemalan decentralization. Int. J. Educ. Dev. 2009, 29, 187-200. [CrossRef]

5. Benavota, A. Policies toward quality education and student learning: Constructing a critical perspective. Eur. J. Soc. Sci. Res. 2012, 25, 67-77. [CrossRef]

6. Paletta, A. Public governance and school performance improving student learning through collaborative public management. Public Manag. Rev. 2012, 14, 1125-1151. [CrossRef]

7. Oancea, A.; Orchard, J. The future of teacher education. J. Philos. Educ. 2012, 46, 574-588. [CrossRef]

8. Georgiou, S. Beliefs of experienced and novice teachers about achievement. Educ. Psychol. Int. J. Exp. Educ. Psychol. 2008, 28, 119-131. [CrossRef]

9. Sheldon, E.; Epstein, J. Counts: Family and community partnerships and mathematics achievement. J. Educ. Res. 2005, 98, 196-207. [CrossRef]

10. Cordero, J.M.; Crespo, E.; Santín, D. Factors affecting educational attainment: Evidence from Spanish PISA 2006. Reg. Sect. Econ. Stud. 2010, 10, 55-76.

11. Coertjens, L.; de Pauw, J.B.; De Maeyer, S.; Van Petegem, P. Do schools make a difference in their students' environmental attitudes and awareness? Evidence from Pisa 2006. Int. J. Sci. Math. Educ. 2010, 8, 497-522. [CrossRef]

12. Willms, J.D. School composition and contextual effects on student outcomes. Teach. Coll. Rec. 2010, 112, 1008-1037.

13. Romer, D. Do Students Go to Class? Should They? J. Econ. Perspect. 1993, 7, 167-174. [CrossRef]

14. Andrietti, V. Does lecture attendance affect academic performance? Panel data evidence for introductory macroeconomics. Int. Rev. Econ. Educ. 2014, 15, 1-16. [CrossRef]

15. Brauer, J. Should class attendance be mandatory? J. Econ. Perspect. 1994, 8, 205-207.

16. Reunitz, P.C. Promoting in-class student involvement in medicinal chemistry. Am. J. Pharm. Educ. 1997, 61, 302-306.

17. Lai, P.; Chan, K.K. Should class attendance be mandatory? Atl. Econ. J. 2000, 28, 377. [CrossRef]

18. Khan, H.U.; Khattak, A.M.; Mahsud, I.U.; Munir, A.; Ali, S.; Khan, M.H.; Saleem, M.; Shah, S.H. Impact of class attendance upon examination results of students in basic medical sciences. J. Ayub Med. Coll. 2002, 15, $56-58$.

19. Kirby, A.; McElroy, B. The effect of attendance on grade for first year economics students in University College Cork. Econ. Soc. Rev. 2003, 34, 311-326.

20. Moore, R.; Jensen, M.; Hatch, J.; Duranczyk, I.; Staats, S.; Koch, L. Showing up: The importance of class attendance for academic success in introductory science courses. Am. Biol. Teach. 2003, 65, 325-329. [CrossRef]

21. Moore, R. Helping students succeed in introductory biology classes: Does improving students' attendance also improve their grades? Bioscene 2003, 29, 17-25. 
22. Silvestri, L. The effect of attendance on undergraduate methods course grades. Education 2003, 123, $483-486$.

23. Perez, J.; Graell, S. Asistencia a clase y rendimiento académico en estudiantes de medicina. La experiencia de la Universidad Autónoma de Barcelona. Educ. Méd. 2004, 7, 85-89. [CrossRef]

24. Stanca, L. The effects of attendance on academic performance: Panel data evidence for introductory microeconomics. J. Econ. Educ. 2006, 37, 251-266. [CrossRef]

25. Purcell, P. Engineering student attendance at lectures: Effect on examination performance. In Proceedings of the International Conference on Engineering Education-ICEE 2007, Coimbra, Portugal, 3-7 September 2017.

26. Zamboanga, B.L.; Padilla-Walker, L.M.; Thompson, R.A.; Wang, S.C. Academic background and course involvement as predictors of exam performance. Teach. Psychol. 2007, 34, 158-162. [CrossRef]

27. Dobkin, C.; Ricard, G.; Justin, M. Skipping class in college and exam performance: Evidence from a regression discontinuity classroom experiment. Econ. Educ. Rev. 2010, 29, 566-575. [CrossRef]

28. Hidayat, L.; Vansal, S.; Kim, E.; Sullivan, M.; Salbu, R. Pharmacy student absenteeism and academic performance. Am. J. Pharm. Educ. 2012, 76, 1-6. [CrossRef] [PubMed]

29. Landin, M.; Pérez, J. Class attendance and academic achievement of pharmacy students in a European University. Curr. Pharm. Teach. Learn. 2015, 7, 78-83. [CrossRef]

30. Mather, C.; Caesar, L.; Chin, C.; Fei, J. Class Attendance and Use of Echo360 in Australia: A Comparison between Undergraduate Nursing and Maritime Disciplines. Procedia Soc. Behav. Sci. 2015, 174, 2839-2845. [CrossRef]

31. Lukkarinen, A.; Koivukangas, P.; Seppälä, T. Relationship between Class Attendance and Student Performance. Procedia Soc. Behav. Sci. 2016, 228, 341-347. [CrossRef]

32. Rejnö, Å.; Nordin, P.; Forsgren, S.; Sundell, Y.; Rudolfsson, G. Nursing students' attendance at learning activities in relation to attainment and passing courses: A prospective quantitative study. Nurse Educ. Today 2017, 50, 36-41. [CrossRef] [PubMed]

33. Cortright, R.; Lujan, H.; Cox, J.; Di Carlo, S. Does sex (female versus male) influence the impact of class attendance on examination performance? Adv. Physiol. Educ. 2011, 35, 416-420. [CrossRef] [PubMed]

34. Stoner, S.C.; Fincham, J.E. Faculty role in classroom engagement and attendance. Am. J. Pharm. Educ. 2012, 76, 75. [CrossRef] [PubMed]

35. Moore, S.; Armstrong, C.; Pearson, J. Lecture absenteeism among students in higher education: A valuable route to understanding student motivation. J. High. Educ. Policy Manag. 2008, 30, 15-24. [CrossRef]

36. Eisen, D.; Schupp, C.; Isserof, R.; Ibrahimi, O.; Ledo, L.; Armstrong, A. Does class attendance matter? Results from a second-year medical school dermatology cohort study. Int. J. Dermatol. 2015, 54, 807-816. [CrossRef] [PubMed]

37. Diaz, R.M. The Impact of Second-Language Learning on the Development of Verbal and Spatial Abilities; Dissertation; Yale University: New Haven, CT, USA, 1983.

38. Armstrong, P.W.; Rogers, J.D. Basic Skills Revisited: The Effects of Foreign Language Instruction on Reading, Math and Language Arts. Learn. Lang. 1997, 2, 20-31.

39. Marburger, D.R. Absenteeism and undergraduate exam performance. J. Econ. Educ. 2001, 32, 99-109. [CrossRef]

40. Marburger, D.R. Does mandatory attendance improve student performance? J. Econ. Educ. 2006, 37, $148-155$. [CrossRef]

41. Cameron, A.C.; Trivedi, P.K. Microeconometrics Using Stata; Stata Press: College Station, TX, USA, 2009.

42. Krohn, J.B.; O'Connor, C.M. Student effort and performance over the semester. J. Econ. Educ. 2005, 36, 3-28. [CrossRef]

43. Self, S. Studying Absenteeism in Principles of Macroeconomics: Do Attendance Policies Make a Difference? Res. Econ. Educ. 2012, 43, 223-234. [CrossRef]

44. Andrietti, V.; Velasco, C. Lecture Attendance, Study Time, and Academic Performance: A Panel Data Study. J. Econ. Educ. 2015, 46, 239-259. [CrossRef]

45. Durden, G.C.; Ellis, L.V. The effects of attendance on student learning in principles of economics. Am. Econ. Rev. Pap. Proc. 1995, 85, 343-346.

46. Devadoss, S.; Foltz, J. Evaluation of factors influencing student class attendance and performance. Am. J. Agric. Econ. 1996, 78, 499-507. [CrossRef] 
47. Wierenga, K.; Winter, S.; Arends, R.; Castro, R.; Dekkers, P.; Eertink, H.; Guido, L.; Leira, J.; Linden, M.; Milinovic, M.; Papez, R.; et al. Deliverable dj5. 1.4: Inter-Nren Roaming Architecture: Description and Development Items; GN2 1RA5; GEANT: Cambridge, CA, USA, 2006; Volume 2.

48. Sanchez, M.; López, G.; Cánovas, O.; Gómez-Skarmeta, A.F. Performance analysis of a cross-layer SSO mechanism for a roaming infrastructure. J. Netw. Comput. Appl. 2009, 32, 808-823. [CrossRef]

49. Pérez-Méndez, A.; Marín-López, R.; López-Millán, G. Providing efficient SSO to cloud service access in AAA-based identity federations. Future Gener. Comput. Syst. 2016, 58, 13-28. [CrossRef]

50. Vedung, E. Public Policy and Program Evaluation; Transaction Publishers: New Brunswick, NJ, USA; London, UK, 2009.

51. Salinas, M.M.; Simancas, R.; Mateos, L.; Murillo, I.P. Cuándo Poner las Presentaciones a Disposición de los Alumnos, Antes o Después de las Clases? EFECTOS Sobre la Satisfacción de los Estudiantes y Sobre los Resultados del Examen. In Proceedings of the IX Jornadas de Docencia en Economía, Universidad de Extremadura, Málaga, Spain, 31 May-1 June 2017.

52. Worthington, D.L.; Levasseur, D.G. To provide or not to provide course PowerPoint slides? The impact of instructor-provided slides upon student attendance and performance. Comput. Educ. 2015, 85, 14-22. [CrossRef]

53. Chen, J.; Lin, T.F. Does downloading PowerPoint slides before the lecture lead to better student achievement? Int. Rev. Econ. Educ. 2008, 7, 9-18. [CrossRef]

54. Chen, J.; Lin, T.F. Does Downloading PowerPoint Slides Before the Lecture Lead to Better Student Achievement?: Reply. Int. Rev. Econ. Educ. 2011, 10, 90-93. [CrossRef]

55. Chen, J.; Lin, T.F. Do Supplemental Online Recorded Lectures Help Students Learn Microeconomics? Int. Rev. Econ. Educ. 2012, 11, 6-15. [CrossRef]

56. Scotchmer, S. Risk Taking and Gender in Hierarchies. Theor. Econ. 2008, 3, 499-524. [CrossRef]

57. Espinosa, M.P.; Gardeazabal, J. Do Students Behave Rationally in Multiple Choice Tests? Evidence from a Field Experiment. J. Econ. Manag. 2013, 9, 107-135. [CrossRef]

58. Cohn, E.; Johnson, E. Class Attendance and Performance in Principles of Economics. Educ. Econ. 2006, 14, 211-233. [CrossRef]

59. Neter, J.; Wasserman, W.; Kutner, M.H. Applied Linear Statistical Models, 5th ed.; McGraw-Hill/Irwin: Columbus, OH, USA, 2004; ISBN-13 978-0-07-310874-2.

60. Byrnes, J.P.; Miller, D.C.; Schafer, W.D. Gender Differences in Risk Taking: A Meta-Analysis. Psychol. Bull. 1999, 125, 367-383. [CrossRef]

61. Prieto, G.; Delgado, A.R. The role of instructions in the variability of sex-related differences in multiple-choice tests. Personal. Individ. Differ. 1999, 27, 1067-1077. [CrossRef]

62. Cadsby, C.B.; Maynes, E. Gender, Risk Aversion, and the Drawing Power of Equilibrium in an Experimental Corporate Takeover Game. J. Econ. Behav. Organ. 2005, 56, 39-59. [CrossRef] 